\title{
Establishing blood gas ranges in healthy bovine neonates differentiated by age, sex, and breed type
}

\author{
Patrick Dillane, ${ }^{*}$ Lea Krump, ${ }^{*}$ Aideen Kennedy, $†$ Ríona G. Sayers, $†$ and Gearóid P. Sayers ${ }^{* 1}$ \\ *Department of Biological and Pharmaceutical Sciences, Institute of Technology Tralee, Tralee, Co. Kerry, Ireland, V92 CX88 \\ †Animal \& Grassland Research and Innovation Centre, Teagasc, Moorepark, Fermoy, Co. Cork, Ireland, P61 C996
}

\begin{abstract}
Calf mortality and morbidity commonly occurs within the first month of life postpartum. Standard health ranges are invaluable aids in diagnostic veterinary medicine to confirm normal or the degree and nature of abnormal parameters in (sub)clinically ill animals. Extensive research has indicated significant differences between the physiologies of neonate and adult cattle, particularly for blood parameters such as $\mathrm{pH}$, base excess, anion gap, and bicarbonate $\left(\mathrm{HCO}_{3}{ }^{-}\right)$. The objective of this research was to determine the influence of age, sex, and breed type, in addition to environmental factors, on the normal blood gas profiles of neonatal calves, and thus develop a scientifically validated reference range accounting for any significant factors. The study was conducted on healthy neonatal calves $(\mathrm{n}=288)$, and completed over a 2-yr period. Individual calf blood gas analysis was conducted for parameters of $\mathrm{pH}$, base excess, $\mathrm{Na}^{+}, \mathrm{K}^{+}, \mathrm{Ca}^{2+}, \mathrm{Cl}^{-}$, glucose, total hemoglobin, $\mathrm{HCO}_{3}{ }^{-}, \mathrm{pCO}_{2}$, anion gap, strong ion difference, and hematocrit levels. Regression procedures examined the combined effect of year, farm, age, breed type, sex, and hours postfeeding on each variable. Significant effects were observed for age, sex, and breed type on several of the blood gas variables. Furthermore, year, farm, and hours postfeeding appeared to have less of an influence on neonatal bovine blood gas profiles. Consequently, specific ranges based on the neonate's age, sex, and breed type will allow for more detailed and accurate diagnosis of health and ill health in neonatal calves.
\end{abstract}

Key words: reference range, healthy neonatal calf, blood gas analysis, calf health, prevention

\section{INTRODUCTION}

The majority of calf mortality and morbidity occurs within the first month of life, with blood gas abnormali-

Received July 5, 2017.

Accepted December 1, 2017.

${ }^{1}$ Corresponding author: gearoid.sayers@staff.ittralee.ie ties commonly accompanying various neonatal diseases (Boden, 2005; Bleul et al., 2007; Smith, 2014). The assessment of ill calves is still commonly based on clinical examination alone; however, the emergence of pen-side blood gas analyzers has facilitated a more accurate approach to assess the degree and nature of blood gas derangement (Russell and Roussel, 2007; Bleul, et al., 2007). Therefore, the development of ad hoc reference ranges for neonates would allow for a more accurate interpretation of health and ill health.

Standard blood gas reference ranges aid clinicians and researchers in identifying and differentiating normal from abnormal parameters, particularly for disease diagnoses purposes (Knowles et al., 2000; Cornell University College of Veterinary Medicine, 2014; AACC, 2015). The most appropriate reference range is one generated from a group of healthy animals with environmental and physiological characteristics as closely related to the target patient as possible (Meyer and Harvey, 2004; Roland et al., 2014). In this regard, Mohri et al. (2007) suggested that separate reference ranges or values are required from a particular age or breed type of a calf.

Various reference ranges for healthy adult cattle, including that for blood gas, have been established (Divers and Peek, 2007; Marshall and Bangert, 2008; Smith, 2009; Wood and Quiroz-Rocha, 2010). Although these have been used extensively and successfully in adult cattle, applying adult ranges to young calves can be misleading due to the blood gas changes that are associated with normal prepubertal physiological development (Rice, 1994; Herfen and Bostedt, 1999; Knowles et al., 2000; Detry et al., 2003). Several studies have indicated significant differences between the physiology of young and adult cattle, particularly for serum $\mathrm{pH}$, bicarbonate $\left(\mathrm{HCO}_{3}{ }^{-}\right)$, base excess $(\mathbf{B E})$, anion gap (AG), and strong ion difference (SID; Adams and Polzin, 1989; Gustin et al., 1997; Lorenz et al., 2005; Koch and Kaske, 2008). Furthermore, genetic (breed type), age, and environmental factors influence hematological and biochemical values in healthy animals (Sayers et al., 2016). 
Table 1. Description of calf husbandry regimens on each study farm for neonatal calves

\begin{tabular}{|c|c|c|c|c|c|c|}
\hline Farm & Breeds $^{1}$ & Housing & Milk feeding system & $\begin{array}{l}\text { Ad libitum } \\
\text { water } \\
\text { available? }\end{array}$ & $\begin{array}{l}\text { Creep feed } \\
\text { available? }\end{array}$ & $\begin{array}{l}\text { Shared } \\
\text { airspace with } \\
\text { adult cattle? }\end{array}$ \\
\hline $\mathrm{A}$ & $\begin{array}{l}\text { HF, JeX, } \\
\text { AbA, LM, } \\
\text { NR }\end{array}$ & $\begin{array}{l}\text { Males and females housed } \\
\text { separately. Individual calf pen } \\
\text { followed by group pens (up } \\
\text { to } 20 \text { animals) at } 3 \mathrm{~d} \text { of age. } \\
\text { Deep straw bedding in all } \\
\text { pens. }\end{array}$ & $\begin{array}{l}\text { Automatic feeders with } \\
\text { an allowance of } 6 \mathrm{~L} \text { of } \\
\text { milk replacer per calf per } \\
\text { day as a routine. }\end{array}$ & Yes & $\begin{array}{l}\text { Yes, from } 1 \\
\text { wk of age }\end{array}$ & No \\
\hline $\mathrm{D}$ & $\begin{array}{l}\mathrm{HF}, \mathrm{JeX} \\
\mathrm{BB}\end{array}$ & $\begin{array}{l}\text { Individual calf pen followed by } \\
\text { group pens (up to } 15 \text { animals) } \\
\text { at } 2 \text { d of age. Deep straw } \\
\text { bedding in all pens. }\end{array}$ & $\begin{array}{l}\text { Manual multicalf } \\
\text { feeding buckets with an } \\
\text { allowance of } 6 \mathrm{~L} \text { of milk } \\
\text { replacer or whole milk } \\
\text { per calf per day. }\end{array}$ & Yes & $\begin{array}{l}\text { Yes, from } 1 \\
\text { wk of age }\end{array}$ & No \\
\hline
\end{tabular}

${ }^{1} \mathrm{HF}=$ Holstein-Friesian; JeX = Jersey cross; NR = Norwegian Red; AbA = Aberdeen Angus; LM = Limousin; BB = Belgian Blue.

Several studies have attempted to develop standard values for biochemical and hematological variables for neonatal calves; however, difficulties relating to sample size, breed variations, and age differentiations constrained their use (Tennant et al., 1974; Dubreuil and Lapierre, 1997; Hugi and Blum, 1997; Egli and Blum, 1998). Therefore, the aim of our research was to evaluate age, sex, and breed type factors that influence blood gas ranges in neonatal calves and to develop tailored reference ranges for this cohort.

\section{MATERIALS AND METHODS}

\section{Sample Population}

A total of 288 samples (263 individual calves, 21 calves repeated twice, and 2 calves sampled 3 times, all at different age points) from healthy neonatal bovines aged 1 ( $>24 \mathrm{~h}$ ) to $30 \mathrm{~d}$, from 3 research farms (farm A: $\mathrm{n}=71$, farm B: $\mathrm{n}=129$, farm $\mathrm{C}: \mathrm{n}=42)$ and $1 \mathrm{com}-$ mercial dairy farm (farm D: $\mathrm{n}=46$ ), were completed over a 2-yr period in $2016(\mathrm{n}=185)$ and $2017(\mathrm{n}=$ 103). A description of husbandry regimens for neonatal calves on each of the study farms is presented in Table 1. Healthy calves on these farms were randomly selected to be enrolled in the study. The inclusion criteria were based on 3 factors: (1) each calf did not have any prior recorded illness; (2) the housing facility of each calf was free of any disease outbreak before analysis; and (3) at the point of analysis, a clinical assessment was undertaken on each calf, incorporating calf demeanor, ear position, mobility, interest in surroundings, suckle reflex, feed intake, and dehydration status. All calves were assessed and scored simultaneously by 2 research veterinarians, and calves that were regarded as clinically healthy were enrolled in the study. Temperature was not recorded.

In addition to farm and year, the sample population of calves were differentiated by age (1-30 d), sex (male $\mathrm{n}$ $=157$, female $\mathrm{n}=131$ ), breed [dairy: Holstein-Friesian $(\mathrm{n}=178)$, Jersey cross $(\mathrm{n}=88)$, Norwegian Red $(\mathrm{n}=$ 2); beef: Aberdeen Angus ( $\mathrm{n}=12)$, Limousin $(\mathrm{n}=7)$, and Belgian Blue $(\mathrm{n}=1)$ ], and hours postfeeding $(<1$, $1-2,2-4,>4 \mathrm{~h})$.

\section{Blood Sampling}

An individual calf was blood sampled by jugular venipuncture on at least 1 but not more than 3 occasions over the duration of the study. A total volume of between 1.5 to $2 \mathrm{~mL}$ of venous blood was taken into labeled heparinized 2.5-mL syringes (Cruinn Diag- 
nostics, Dublin, Ireland). All visible air bubbles were expelled immediately after sampling and the tip of each syringe was capped after blood sampling. The syringes were stored at room temperature for no longer than 5 min. Blood samples were placed on a bottle roller and continuously agitated for at least $20 \mathrm{~s}$ to prevent formation of microclots. Before analyzing, all remaining air bubbles were carefully removed from the blood sample. A benchtop Rapidpoint 500 (Siemens, Munich, Germany) analyzer was used to test all samples using a standard temperature setting of $37^{\circ} \mathrm{C}$. Blood parameters reported by the analyzer included $\mathrm{pH}$, standard $\mathrm{HCO}_{3}{ }^{-}(\mathrm{m} M)$, actual $\mathrm{HCO}_{3}{ }^{-}(\mathrm{m} M)$, partial pressure of carbon dioxide $\left(\mathbf{p C O}_{2} ; \mathrm{kPa}\right), \mathrm{BE}(\mathrm{m} M), \mathrm{Na}^{+}(\mathrm{m} M)$, $\mathrm{K}^{+}(\mathrm{m} M), \mathrm{Ca}^{2+}(\mathrm{m} M), \mathrm{Cl}^{-}(\mathrm{m} M)$, glucose $(\mathrm{mM})$, total hemoglobin $(\mathbf{t H b} ; \mathrm{g} / \mathrm{dL})$, and $\mathrm{AG}(\mathrm{m} M)$. This analyzer uses ion-selective electrodes for analysis of $\mathrm{pH}$, sodium, potassium, ionized calcium, and chloride, and modified potentiometry for $\mathrm{pCO}_{2}$ (Severinghaus electrode) and glucose (enzyme electrodes). The $\mathrm{BE}$ and $\mathrm{AG}$ were calculated using blood gas machine algorithms; the AG algorithm used was $\left[\mathrm{Na}^{+}+\mathrm{K}^{+}\right]-\left[\mathrm{Cl}^{-}+\right.$standard $\mathrm{HCO}_{3}{ }^{-}$], and $\mathrm{BE}$ was calculated as [standard $\mathrm{HCO}_{3}{ }^{-}$] - actual $\mathrm{HCO}_{3}{ }^{-}$]. The SID was calculated based on the combined electrolyte concentration of $\left[\mathrm{Na}^{+}\right]+\left[\mathrm{K}^{+}\right]$ $-\left[\mathrm{Cl}^{-}\right]$. The hematocrit (PCV) levels in individual calves was calculated using a Hemo Vet Hemoglobin Analyzer (EKF Diagnostics, Cardiff, United Kingdom). The Hemo-Vet analyzer uses a photometric azidemethemoglobin method using sodium azide-coated cuvettes; the calculation of the PCV value is based on the concentration of hemoglobin, a relationship previ- ously investigated by Turkson and Ganyo (2015), and PCV was calculated using the algorithm [hemoglobin] $\times 0.029$. A total volume of $10 \mu \mathrm{L}$ of the calf's original blood sample was added to a cuvette, analyzed, and calculated as a volume percentage of red blood cells of total blood volume. Analytical performance data for the Rapidpoint 500 and Hemo Vet Analyzer are supplied in Supplemental Tables S1 and S2 in the Supplemental Data (https://doi.org/10.3168/jds.2017-13445). No specific validation data are currently available for the use of bovine blood with the Rapidpoint or the Hemo-Vet analyzers.

\section{Statistical Calculation of Reference Ranges}

All reference ranges established agree with the American Society for Veterinary Clinical Pathology guidelines for the determination of reference intervals in veterinary species (Friedrichs et al., 2012). Preliminary steps established the stability of the variance for each of the continuous blood gas variables based on a Shapiro-Wilks W-test, including a visual examination of ladder of powers histograms for each of the variables. Where normality was not identified, a transformation step was applied. In this case, a natural logarithm (ln) transformation was applied to standard $\mathrm{HCO}_{3}{ }^{-}$, actual $\mathrm{HCO}_{3}{ }^{-}$, tHb, and $\mathrm{PCV}$, a cubed transformation was applied to $\mathrm{Na}^{+}$and $\mathrm{AG}$, and square root of the inverse variable transformation was applied to $\mathrm{Ca}^{2+}$. The mean and standard deviation of each of the variables was obtained, and $90 \%$ confidence intervals determined by mean \pm 1.64 (SD) (Kirkwood and Sterne, 2003).

Table 2. Summary statistics for non-temperature-corrected venous blood gas variables for healthy neonatal calves $(\mathrm{n}=288$; pooled data)

\begin{tabular}{lccccc}
\hline Blood gas variable $^{1}$ & Mean & SD & SEM & Minimum & Maximum \\
\hline pH & 7.419 & 0.028 & 0.002 & 7.343 & 7.503 \\
Standard $\mathrm{HCO}_{3}^{-}(\mathrm{m} M)^{2}$ & $29.9^{3}$ & & & 23.9 & 38.7 \\
${\text { Actual } \mathrm{HCO}_{3}{ }^{-}(\mathrm{m} M)^{2}}_{\mathrm{pCO}_{2}(\mathrm{kPa})}$ & $32.1^{3}$ & & & 25.4 & 41.5 \\
$\mathrm{Base}^{2}$ excess $(\mathrm{m} M)$ & 6.80 & 0.625 & 0.037 & 5.33 & 9.03 \\
Anion gap $(\mathrm{m} M)^{4}$ & 6.7 & 2.496 & 0.147 & -0.1 & 15.5 \\
$\mathrm{SID}(\mathrm{m} M)$ & $12.4^{3}$ & & & 5.6 & 20.2 \\
$\mathrm{Na}^{+}(\mathrm{m} M)^{4}$ & 44.1 & 2.856 & 0.168 & 33.2 & 50.4 \\
$\mathrm{~K}^{+}(\mathrm{m} M)$ & $136.8^{3}$ & & & 131.7 & 142.7 \\
$\mathrm{Cl}^{-}(\mathrm{m} M)$ & 4.77 & 0.390 & 0.023 & 3.67 & 6.20 \\
$\left.\mathrm{Glucose}^{2} \mathrm{~m} M\right)$ & 97 & 2.441 & 0.144 & 91 & 106 \\
$\mathrm{Ca}^{2+}(\mathrm{m} M)^{5}$ & 6.1 & 1.373 & 0.081 & 3.0 & 13.0 \\
Total hemoglobin $(\mathrm{g} / \mathrm{dL})^{2}$ & $1.26^{3}$ & & & 1.09 & 1.42 \\
Hematocrit $(\%)^{2}$ & $11.1^{3}$ & & & 6.4 & 15.4 \\
\hline
\end{tabular}

${ }^{1} \mathrm{pCO}_{2}=$ partial pressure of carbon dioxide; SID $=$ strong ion difference.

${ }^{2}$ Logarithm transformation.

${ }^{3}$ Geometric mean.

${ }^{4}$ Cubic transformation.

${ }^{5}$ Inverse square transformation. 


\section{Statistical Analysis}

Statistical procedures were applied to determine the association between 14 dependent blood gas variables and the combined effect of (1) age (grouped as 1-10 and 11-30 d), (2) year of assessment (2016 and 2017), (3) sex, (4) breed type (dairy and beef-dairy breeds, incorporating Holstein Friesians, Norwegian Red, and Jersey cross; and beef breeds incorporating Aberdeen Angus, Limousin, and Belgian Blue), (5) farm (A, B C, and D), and (6) hours postfeeding (graded as 1-2, 2-4, and $>4 \mathrm{~h}$ ). To comparatively assess and describe the combined effect of the independent variables age, year, sex, breed type, farm, and hours postfeeding on each of the blood gas measurements, manual backward elimination (based on $P>0.30$ ) stepwise regression procedures were used. In total, 14 models were developed for blood gas parameters $\mathrm{pH}$, standard $\mathrm{HCO}_{3}{ }^{-}$, actual $\mathrm{HCO}_{3}{ }^{-}$, $\mathrm{pCO}_{2}, \mathrm{BE}, \mathrm{tHb}, \mathrm{PCV}$, glucose, $\mathrm{Na}^{+}, \mathrm{K}^{+}, \mathrm{Cl}^{-}, \mathrm{Ca}^{2+} \mathrm{AG}$, and SID. We considered $P$-values of $\leq 0.05$ statistically significant. All data management of the results were completed using Excel (Office 2016, Microsoft Corp., Redmond, WA). Normality and statistical procedures were carried out using Stata SE v12.1. (Stata Corp. LP, College Station, TX).

\section{Study Approval}

This study was approved by the Teagasc Animal Ethics Committee (TAEC 81/2014); all procedures were classified as mild. Procedures were authorized and carried out in accordance with the Health Products Regulatory Authority (HPRA) of Ireland (AE19132/P037).

Table 3. Manual backward elimination stepwise regression procedure between blood gas variables and independent variables ${ }^{1}$

\begin{tabular}{|c|c|c|c|c|c|c|}
\hline \multirow[b]{2}{*}{ Item } & \multicolumn{2}{|c|}{$\begin{array}{l}\text { Age } \\
(\text { relative to calves } 1-10 \mathrm{~d})\end{array}$} & \multicolumn{2}{|c|}{$\begin{array}{l}\text { Sex } \\
\text { (relative to female) }\end{array}$} & \multicolumn{2}{|c|}{$\begin{array}{c}\text { Breed type } \\
\text { (relative to dairy breeds) }\end{array}$} \\
\hline & $\mathrm{CV}(\mathrm{SEM})$ & $P$-value & $\mathrm{CV}(\mathrm{SEM})$ & $P$-value & $\mathrm{CV}(\mathrm{SEM})$ & $P$-value \\
\hline$\overline{\mathrm{pH}}$ & $-0.008(0.004)$ & 0.038 & $-0.010(0.003)$ & 0.002 & $0.010(0.006)$ & 0.117 \\
\hline Standard $\mathrm{HCO}_{3}{ }^{-2}$ & $-0.028(0.010)$ & 0.005 & $-0.023(0.009)$ & 0.014 & $0.066(0.018)$ & $<0.001$ \\
\hline Actual $\mathrm{HCO}_{3}^{-2}$ & $-0.022(0.010)$ & 0.042 & $-0.024(0.009)$ & 0.014 & $0.070(0.019)$ & $<0.001$ \\
\hline $\mathrm{pCO}_{2}$ & 3 & - & - & - & $0.303(0.141)$ & 0.032 \\
\hline Base excess & $-0.719(0.170)$ & $<0.001$ & - & - & $-0.660(0.304)$ & 0.031 \\
\hline Anion gap ${ }^{4}$ & $-0.730(0.318)$ & 0.023 & $-0.759(0.292)$ & 0.010 & $2.11(0.571)$ & $<0.001$ \\
\hline SID & - & - & - & - & $-0.082(0.036)$ & 0.024 \\
\hline $\mathrm{Na}^{+4}$ & $-0.063(0.024)$ & 0.008 & - & - & $-0.078(0.042)$ & 0.064 \\
\hline $\mathrm{K}^{+}$ & $72,374(14,314)$ & $<0.001$ & $-56,063(13,088)$ & $<0.001$ & $-43,913(25663)$ & 0.088 \\
\hline $\mathrm{Cl}^{-}$ & $-0.210(0.048)$ & $<0.001$ & $0.187(0.045)$ & $<0.001$ & $-0.136(0.085)$ & 0.112 \\
\hline Glucose & $1.920(0.292)$ & $<0.001$ & - & - & $-1.596(0.536)$ & 0.003 \\
\hline $\mathrm{Ca}^{2+5}$ & - & - & $-0.009(0.007)$ & 0.236 & - & - \\
\hline Total hemoglobin ${ }^{2}$ & - & - & - & - & $-889.3(279.9)$ & 0.002 \\
\hline \multirow[t]{3}{*}{ Hematocrit $^{2}$} & $-0.901(0.333)$ & 0.007 & $-0.994(0.335)$ & 0.003 & - & - \\
\hline & \multicolumn{2}{|c|}{ Year (relative to born in 2016) } & \multicolumn{2}{|l|}{ Farm } & \multicolumn{2}{|c|}{ Hours postfeeding } \\
\hline & $\mathrm{CV}(\mathrm{SEM})$ & $P$-value & $\mathrm{CV}(\mathrm{SEM})$ & $P$-value & $\mathrm{CV}(\mathrm{SEM})$ & $P$-value \\
\hline $\mathrm{pH}$ & $0.008(0.006)$ & 0.158 & $-0.006(0.003)$ & 0.052 & - & - \\
\hline Standard $\mathrm{HCO}_{3}^{-2}$ & $-0.046(0.016)$ & 0.005 & $0.014(0.008)$ & 0.082 & - & - \\
\hline Actual $\mathrm{HCO}_{3}^{-2}$ & $-0.066(0.017)$ & $<0.001$ & $0.023(0.008)$ & 0.006 & - & - \\
\hline $\mathrm{pCO}_{2}$ & $-0.604(0.129)$ & $<0.001$ & $0.272(0.062)$ & $<0.001$ & - & - \\
\hline Base excess & $0.633(0.289)$ & 0.029 & $-0.187(0.144)$ & 0.197 & $-0.247(0.124)$ & 0.056 \\
\hline Anion gap ${ }^{4}$ & $-1.519(0.515)$ & 0.003 & $0.464(0.259)$ & 0.075 & - & - \\
\hline SID & - & - & - & - & - & - \\
\hline $\mathrm{Na}^{+4}$ & $0.060(0.041)$ & 0.137 & $-0.036(0.019)$ & 0.065 & $0.023(0.017)$ & 0.166 \\
\hline $\mathrm{K}^{+}$ & $-70,019(23,138)$ & 0.003 & $34,280(11,642)$ & 0.004 & - & - \\
\hline $\mathrm{Cl}^{-}$ & $-0.203(0.081)$ & 0.013 & $0.119(0.040)$ & 0.003 & $0.044(0.036)$ & 0.216 \\
\hline Glucose & $-1.340(0.484)$ & 0.006 & $0.580(0.243)$ & 0.017 & - & - \\
\hline $\mathrm{Ca}^{2+5}$ & - & - & - & - & $0.014(0.005)$ & 0.007 \\
\hline Total hemoglobin ${ }^{2}$ & $1,049.0(256.7)$ & $<0.001$ & $-265.53(123.48)$ & 0.032 & - & - \\
\hline Hematocrit $^{2}$ & - & - & - & - & - & - \\
\hline
\end{tabular}

${ }^{1}$ Significant coefficients are presented in bold. $\mathrm{pCO}_{2}=$ partial pressure of carbon dioxide; $\mathrm{SID}=$ strong ion difference.

${ }^{2} \ln$ (variable).

${ }^{3}$ Indicates variable eliminated from the model construct $(P>0.20)$.

${ }^{4}(\text { variable })^{3}$.

${ }^{5}$ Square root of $1 /$ (variable). 
Table 4. Suggested reference range for combined non-temperaturecorrected venous blood gas values for healthy neonatal calves

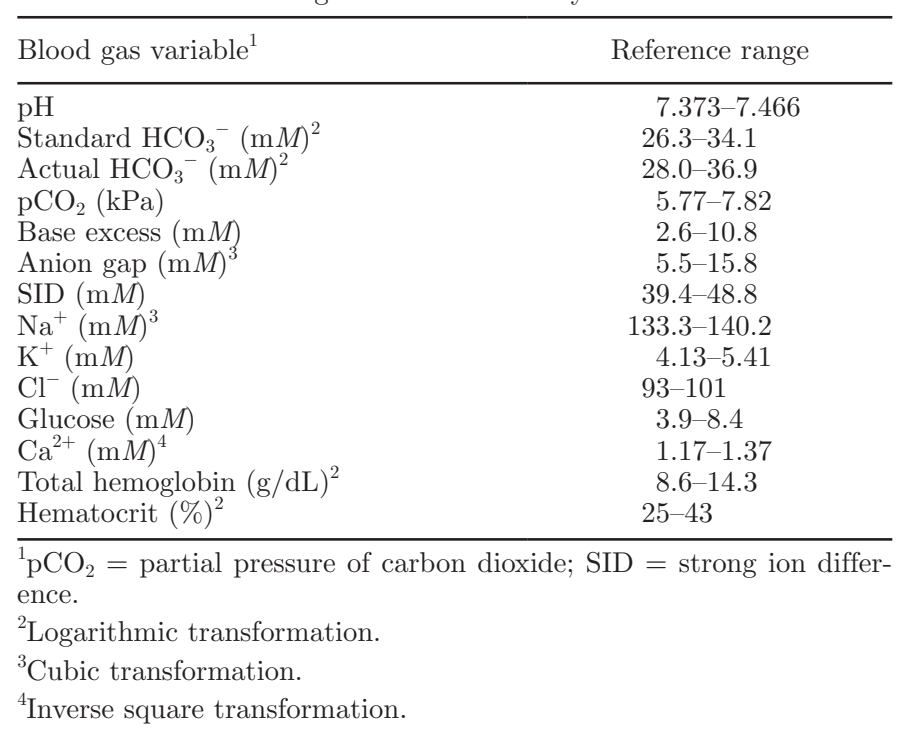

\section{RESULTS}

The descriptive statistics for the pooled data are presented in Table 2. The results from the regression analysis, as shown in Table 3, showed that age, sex, and year had the greatest number of significant associations $(P \leq 0.05)$ with the blood gas variables, indicating that these variables, in particular, influence normal reference ranges. Breed type, farm, and hours postfeeding also showed significance for some variables.
The age of the calf influenced the most blood gas values. Older neonates (11-30 d) had significantly lower blood gas values relative to their younger peers for variables $\mathrm{pH}$, standard $\mathrm{HCO}_{3}^{-}$, $\mathrm{BE}, \mathrm{SID}, \mathrm{K}^{+}$, glucose, and PCV, with significantly elevated values for $\mathrm{Na}^{+}$and $\mathrm{Cl}^{-}$. Similarly, the sex of the calf showed, on average, that the male calves have significantly decreased values for blood serum $\mathrm{pH}$, standard $\mathrm{HCO}_{3}{ }^{-}, \mathrm{BE}, \mathrm{Na}^{+}$, and SID, and have increased values for $\mathrm{K}^{+}$compared with their female counterparts. The year of birth indicated that calves born in 2017 have significantly decreased values for blood serum standard $\mathrm{HCO}_{3}{ }^{-}, \mathrm{BE}, \mathrm{Na}^{+}, \mathrm{K}^{+}$, and $\mathrm{Cl}^{-}$, and have increased values for glucose and $\mathrm{AG}$ compared with the 2016-born calves.

A standard pooled reference range $(90 \% \mathrm{CI})$, incorporating all calves, is presented in Table 4, whereas specific ranges (90\% CI), differentiated by age and sex, are presented in Table 5. Additional summary statistics relating to Table 5 and references ranges differentiated by breed type are presented in Supplemental Data (https://doi.org/10.3168/jds.2017-13445).

\section{DISCUSSION}

Blood gas values coupled with appropriate reference ranges are an effective and useful indicator of health in animals. The results of our study indicate differences in the blood gas profiles of healthy calves up to $30 \mathrm{~d}$ postpartum, principally influenced by the calf's age, sex, and breed type, which significantly affect the normal

Table 5. Suggested ranges for non-temperature-corrected venous blood gas values for healthy neonatal female and male calves at 1 to 10 and 11 to $30 \mathrm{~d}$

\begin{tabular}{|c|c|c|c|c|}
\hline \multirow[b]{2}{*}{ Blood gas variable $^{1}$} & \multicolumn{2}{|c|}{ Female reference range } & \multicolumn{2}{|c|}{ Male reference range } \\
\hline & $1-10 \mathrm{~d}^{2}$ & $11-30 \mathrm{~d}^{3}$ & $1-10 d^{4}$ & $11-30 \mathrm{~d}^{5}$ \\
\hline $\mathrm{pH}$ & $7.394-7.468$ & $7.364-7.473$ & $7.368-7.462$ & $7.375-7.459$ \\
\hline Standard $\mathrm{HCO}_{3}^{-}(\mathrm{m} M)$ & $27.5-33.7$ & $26.1-33.9$ & $25.4-35.0$ & $26.1-32.8$ \\
\hline Actual $\mathrm{HCO}_{3}^{-}(\mathrm{m} M)$ & $28.8-36.4$ & $28.1-36.7$ & $26.9-37.8$ & $27.7-35.4$ \\
\hline $\mathrm{pCO}_{2}(\mathrm{kPa})$ & $5.73-7.66$ & $5.82-7.85$ & $5.73-8.07$ & $5.84-7.57$ \\
\hline Base excess $(\mathrm{m} M)$ & $3.9-10.5$ & $2.5-10.9$ & $1.6-11.7$ & $2.7-9.6$ \\
\hline Anion gap $(\mathrm{m} M)$ & $7.8-16.3$ & $8.7-15.2$ & $6.7-17.1$ & $7.4-15.3$ \\
\hline $\operatorname{SID}(\mathrm{m} M)$ & $40.3-49.2$ & $40.0-48.7$ & $39.5-49.1$ & $38.2-47.7$ \\
\hline $\mathrm{Na}^{+}(\mathrm{m} M)$ & $133.3-139.9$ & $134.7-141.3$ & $132.5-139.2$ & $134.2-139.3$ \\
\hline $\mathrm{K}^{+}(\mathrm{m} M)$ & $4.33-5.40$ & $3.94-5.11$ & $4.33-5.54$ & $4.16-5.37$ \\
\hline $\mathrm{Cl}^{-}(\mathrm{m} M)$ & $92-101$ & 95-101 & $93-100$ & $95-103$ \\
\hline Glucose $(\mathrm{m} M)$ & $4.2-9.5$ & $3.9-7.2$ & $3.9-9.0$ & $4.3-7.4$ \\
\hline $\mathrm{Ca}^{2+}(\mathrm{m} M)$ & $1.16-1.36$ & $1.15-1.35$ & $1.17-1.37$ & $1.18-1.35$ \\
\hline Total hemoglobin (g/dL) & $8.7-14.6$ & $9.1-13.8$ & $8.1-14.2$ & $8.3-13.2$ \\
\hline Hematocrit (\%) & $24-44$ & $25-40$ & $24-44$ & $23-40$ \\
\hline
\end{tabular}


blood gas profile, thus contributing to the thresholds and width of blood gas ranges of a neonate calf.

Adopting current blood gas reference ranges for healthy adult cattle (Divers and Peek, 2007; Stämpfli et al., 2012; Smith, 2014) to assess any blood gas derangements in neonates may be unwise, as differences exist between the ranges presented here and for adult bovines (Divers and Peek, 2007; Stämpfli et al., 2012; Smith 2014). This agrees with previous studies, which outlined similar findings regarding standard ranges for neonates (Rice, 1994; Gustin et al., 1997; Lorenz et al., 2005; Sayers et al., 2016).

The hypothesis that reference ranges must be as specific to the target patient, regarding age and sex, as possible (Meyer and Harvey, 2004; Roland et al., 2014) has been corroborated in our study. Age was shown to have the most significant effect on blood gas variables. It has been demonstrated previously that immediately after a eutocic birth all calves display a minor metabolic-respiratory acidosis (Rice, 1994; Herfen and Bostedt, 1999), with $\mathrm{pH}$ values increasing during the first month of life to reach standard adult values (Gustin et al., 1997; Cambier et al., 2000). In the assessment of age as an independent variable in our study, a single cut-off point of $10 \mathrm{~d}$ was applied, which was based on the median point of the data and preliminary evidence of significant group differences between the groups for blood gas variables $\mathrm{pH}$ and $\mathrm{HCO}_{3}{ }^{-}$. The fact the 2 age categories used here showed significant differences for 10 of the 14 blood gas variables may pinpoint to a physiological point of change in the blood of the calf's development at approximately $10 \mathrm{~d}$ of age.

The influence of sex on the blood gas variables was also evident. In our study, male calves had a lower $\mathrm{pH}$ than their female counterparts across the different age categories. Similarly, male calves have lower BE than female calves at birth, which decreased with time for both sexes, as reported previously (Lorenz et al., 2005). The breed type of the animal also influences a healthy blood gas profile and, based on the evidence in our study, justifies the development of breed specific ranges. Whereas broad categories of combined dairy and combined beef breeds were used here, to account for the low number of beef breed numbers, it is evident that breed type can affect blood gas values (Meyer and Harvey, 2004; Roland et al., 2014).

The significant associations of year of sampling and farm on the healthy blood gas variables could be due to undetermined environmental or management influences. Possible sources of these environmental factors include location, ambient temperature, herd-related stress factors, and so on (Wood and Quiroz-Rocha, 2010; Krimer, 2011). These variations can influence the physiology of the calf, thus affecting their normal biochemical and hematological values. Furthermore, it has been shown that newborn calves, in a high-infection pressure environment, can have significantly lower mean blood gas values compared with calves in disease-free environments (Sayers et al., 2016). Whereas we made selection efforts to reduce the effect of this variable, it may be impossible to eliminate it under normal husbandry conditions and could account for year and farm effects. The fact that the time of feeding significantly influenced both blood glucose and $\mathrm{Ca}^{2+}$ levels is not surprising, and has been demonstrated previously (Reece and Wahlstrom, 1972; Bini et al., 1989; Herfen and Bostedt, 1999; Smith and Berchtold, 2014). It is unfeasible to account for the effect of all these independent environmental variables, (year, farm, hours postfeeding, and other undetermined residual factors); however, this issue highlights the limitations of reference ranges. Users should be mindful of these limitations and should note that reference ranges are simply a tool to assess the health status of a patient (Smith, 2009; AACC, 2015). Blood gas values from neonatal calves bordering the lower or upper limits of ranges, should be assessed with the clinical health of the animal in mind.

A combined reference range is presented to assess normal parameters in neonatal calves where characteristics of the calf, such as age or breed type, may be unknown or ambiguous. A previous study (Sayers et al., 2016), investigating a predicted $\mathrm{pH}$ point at which a calf would be determined as clinically ill, suggested that a lower $\mathrm{pH}$ limit closer to 7.36 to be appropriate. This proposed value is in line with the value calculated from our study and with previously published normal values for a neonate calf (Stämpfli et al., 2012). However, it is recommended when the calf's sex, age, or breed type is known, that those ranges be used (Meyer and Harvey, 2004; Smith, 2009; Roland et al., 2014) to more precisely diagnose any possible health issues of a potentially ill calf.

The use of nonvalidated equipment for bovine blood in our study, as well as adopting a standard temperature setting of $37^{\circ} \mathrm{C}$, presents limitations to the current findings. Both analyzers are widely used in the veterinary field and, despite the repeatability of the results in our study, equipment validation is required. The influence of body temperature on the values of some blood gas parameters, most notably $\mathrm{pH}$ and $\mathrm{pCO}_{2}$, or $\mathrm{O}_{2}$ in the case of arterial blood gases, has been previously investigated (Bleul et al., 2007). This is particularly important in the context of blood gas assessment of a hypo- or hyperthermic animal, where the consensus is that temperature correction should be applied (Jones et al., 1989; Bacher, 2005; Higgins, 2016). The neces- 
sity for temperature correction within the euthermic range has not be determined for animals and is deemed unnecessary in humans (Bisson and Younker, 2006; Goldsmith et al., 2016); therefore, the effect of the absence of temperature correction in our study cannot be defined.

\section{CONCLUSIONS}

Blood gas analysis is an invaluable diagnostic tool for establishing the health status of an animal. The ranges developed in this study facilitate accurate and tailored assessment of the health of neonates, differentiated by age, sex, and breed type.

\section{ACKNOWLEDGMENTS}

The authors thank all the farm staff at Teagasc Moorepark (Co. Cork, Ireland) and the commercial farm for access to and care of calves included in the study.

\section{REFERENCES}

Adams, L. G., and D. J. Polzin. 1989. Mixed acid-base disorders. Vet. Clin. North Am. Small Anim. Pract. 19:307-326.

American Association for Clinical Chemistry (AACC). 2015. Reference ranges and what they mean. Accessed Mar. 29, 2017. https:// labtestsonline.org/understanding/features/ref-ranges/start/1.

Bacher, A. 2005. Effects of body temperature on blood gases. Intensive Care Med. 31:24-27.

Bini, P. P., B. Floris, G. M. Vacca, and P. Nuvole. 1989. Hematochemical parameters in calves before, during and after weaning to a regular diet. Boll. Soc. Ital. Biol. Sper. 65:61-68.

Bisson, J., and J. Younker. 2006. Correcting arterial blood gases for temperature: (When) Is it clinically significant? Nurs. Crit. Care $11: 232-238$

Bleul, U., B. Lejeune, S. Schwantag, and W. Kahn. 2007. Blood gas and acid-base analysis of arterial blood in 57 newborn calves. Vet. Rec. 161:688-691.

Boden, E. 2005. Calf health. Page 183 in Black's Veterinary Dictionary. 21st ed. A \& C Black, London, UK.

Cambier, C., T. Clerbaux, B. Detry, D. Beerens, A. Frans, and P. Gustin. 2000. Blood oxygen binding in double-muscled calves and dairy calves with conventional muscle conformation. Am. J. Vet. Res. 61:299-304.

Cornell University College of Veterinary Medicine. 2014. Venous blood gas and electrolyte reference intervals. Accessed Apr. 11, 2017. https://ahdc.vet.cornell.edu/sects/clinpath/reference/blood.cfm.

Detry, B., C. Cambier, A. Frans, P. Gustin, and T. Clerbaux. 2003. Calculation of bovine haemoglobin oxygen saturation by algorithms integrating age, haemoglobin content, blood $\mathrm{pH}$, partial pressures of oxygen and carbon dioxide in the blood, and temperature. Vet. J. 165:258-265.

Divers, T., and S. Peek. 2007. The clinical examination. Page 14 in Rebhun's Diseases of Dairy Cattle. Saunders, Philadelphia, PA.

Dubreuil, P., and H. Lapierre. 1997. Biochemistry reference values for Quebec lactating dairy cows, nursing sows, growing pigs and calves. Can. J. Vet. Res. 61:235-239.

Egli, C. P., and J. W. Blum. 1998. Clinical, haematological, metabolic and endocrine traits during the first three months of life of suck- ling simmentaler calves held in a cow-calf operation. Zentralbl. Veterinarmed. A 45:99-118.

Friedrichs, K. R., K. Harr, K. Freeman, B. Szladovits, R. Walton, K. Barnhart, and J. Blanco-Chavez. 2012. ASVCP reference interval guidelines: determination of de novo reference intervals in veterinary species and other related topics. Vet. Clin. Pathol. 41:441-453.

Goldsmith, J., E. Karotkin, G. Suresh, and M. Keszler. 2016. Assessing the accuracy of a blood gas result. Page 96 in Assisted Ventilation of the Neonate. 6th ed. Elsevier, Amsterdam, the Netherlands.

Gustin, P., B. Detry, A. Robert, M. L. Cao, F. Lessire, C. Cambier, V. Katz, M. Ansay, A. Frans, and T. Clerbaux. 1997. Influence of age and breed on the binding of oxygen to red blood cells of bovine calves. J. Appl. Physiol. 82:784-790.

Herfen, K., and H. Bostedt. 1999. Acid-base status in newborn calves during the first days of life considering different states of vitality. Berl. Munch. Tierarztl. Wochenschr. 112:166-171.

Higgins, C. 2016. Temperature correction of blood gas and $\mathrm{pH}$ measurement - an unresolved controversy. Accessed Oct. 18, 2017. https://acutecaretesting.org/en/articles/temperature-correction -of-blood-gas-and-ph-measurement--an-unresolved-controversy.

Hugi, D., and J. W. Blum. 1997. Changes of blood metabolites and hormones in breeding calves associated with weaning. Zentralbl. Veterinarmed. A 44:99-108.

Jones, J. H., C. Taylor, A. Lindholm, R. Straub, K. Longworth, and R. Karas. 1989. Blood gas measurements during exercise: errors due to temperature correction. J. Appl. Physiol. 67:879-884.

Kirkwood, B., and J. Sterne. 2003. Percentage points of normal distribution, and reference ranges. Pages 47-49 in Essential Medical Statistics. 2nd ed. Blackwell Science, Oxford, UK.

Knowles, T. G., J. E. Edwards, K. J. Bazeley, S. N. Brown, A. Butterworth, and R. D. Warriss. 2000. Changes in the blood biochemical and haematological profile of neonatal calves with age. Vet. Rec. 147:593-598

Koch, A., and M. Kaske. 2008. Clinical efficacy of intravenous hypertonic saline solution or hypertonic bicarbonate solution in the treatment of inappetent calves with neonatal diarrhea. J. Vet. Intern. Med. 22:202-211.

Krimer, P. M. 2011. Generating and interpreting test results: Test validity, quality control, reference values, and basic epidemiology. Pages 365-382 in Duncan and Prasse's Veterinary Laboratory Medicine: Clinical Pathology. 5th ed. Wiley, Chichester, UK.

Lorenz, I., A. Gentile, and W. Klee. 2005. Investigations of D-lactate metabolism and the clinical signs of D-lactataemia in calves. Vet. Rec. 156:412-415.

Marshall, W., and S. Bangert. 2008. The interpretation of biochemical data: Reference values. Page 19 in Clinical Chemistry: Metabolic and Clinical Aspects. 2nd ed. Elsevier, Philadelphia, PA.

Meyer, D. J., and J. W. Harvey. 2004. Interpretation and diagnosis. Page 5 in Veterinary Laboratory Medicine. Saunders, St. Louis. MO.

Mohri, M., K. Sharifi, and S. Eidi. 2007. Hematology and serum biochemistry of Holstein dairy calves: Age related changes and comparison with blood composition in adults. Res. Vet. Sci. 83:30-39.

Reece, W. O., and J. D. Wahlstrom. 1972. Variations in plasma composition of calves: Relationship of electrolyte, glucose, and urea nitrogen concentration to calf age, ration, and feeding time. Am. J. Vet. Res. 33:2175-2178.

Rice, L. E. 1994. Dystocia-related risk factors. Vet. Clin. North Am. Food Anim. Pract. 10:53-68.

Roland, L., M. Drillich, and M. Iwersen. 2014. Hematology as a diagnostic tool in bovine medicine. J. Vet. Diagn. Invest. 26:592-598.

Russell, K. E., and A. J. Roussel. 2007. Evaluation of the ruminant serum chemistry profile. Vet. Clin. North Am. Food Anim. Pract. 23:403-426.

Sayers, R. G., A. Kennedy, L. Krump, G. P. Sayers, and E. Kennedy. 2016. An observational study using blood gas analysis to assess neonatal calf diarrhoea and subsequent recovery with a European Commission-compliant oral electrolyte solution. J. Dairy Sci. 99:4647-4655. 
Smith, B. P. 2009. Clinical chemistry tests. Pages 375-398 in Large Animal Internal Medicine. 4th ed. Mosby, Maryland Heights, MO.

Smith, B. P. 2014. Assessing the welfare of the individual animal or herd. Pages 11-12 in Large Animal Internal Medicine. 5th ed. Mosby, Maryland Heights, MO.

Smith, G. W., and J. Berchtold. 2014. Fluid therapy in calves. Vet. Clin. North Am. Food Anim. Pract. 30:409-427.

Stämpfli, H., O. Oliver, and J. K. Pringle. 2012. Clinical evaluation of an oral electrolyte solution formulated based on strong ion difference (SID) and using propionate as the organic anion in the treatment of neonatal diarrheic calves with strong ion acidosis. Open. J. Vet. Med. 2:34-39. https://doi.org/10.4236/ojvm.2012.21006.
Tennant, B., D. Harrold, M. Reina-Guerra, J. W. Kendrick, and R. C. Laben. 1974. Hematology of the neonatal calf: Erythrocyte and leukocyte values of normal calves. Cornell Vet. 64:516-532.

Turkson, P. K., and E. Ganyo. 2015. Relationship between haemoglobin concentration and packed cell volume in cattle blood samples. Onderstepoort J. Vet. Res. 82:863.

Wood, D., and G. F. Quiroz-Rocha. 2010. Normal hematology of cattle. Pages 829-835 in Schalm's Veterinary Hematology. 6th ed. Wiley, Ames, IA. 